\title{
Interação genótipo $x$ ambiente em genótipos de cafeeiro Mundo Novo por modelos não lineares e multiplicativos
}

\author{
Vinicius Teixeira Andrade ( $\left.{ }^{*}\right)$; Juliana Costa de Rezende (2); César Elias Botelho $\left({ }^{3}\right)$; \\ Gladyston Rodrigues Carvalho (3); Flavia Maria Avelar Gonçalves ( $\left.{ }^{1}\right)$; Alex Mendonça de Carvalho $\left(^{2}\right)$ \\ (1) Universidade Federal de Lavras (UFLA), Departamento de Biologia, 3037, 37200-000, Lavras (MG), Brasil. \\ (2) UFLA, Departamento de Agricultura, 37200-000, Lavras (MG), Brasil. \\ (3) Empresa de Pesquisa Agropecuária de Minas Gerais, Unidade Regional do Sul de Minas, 176, 37200-000, Lavras (MG), Brasil. \\ (*) Autor correspondente: viniciustandrade.vta@gmail.com
}

Recebido: 19/jun./2013; Aceito: 10/nov./2013

\begin{abstract}
Resumo
Este trabalho teve por objetivo avaliar a adaptabilidade e estabilidade fenotípica da produtividade de genótipos do grupo Mundo Novo pelos métodos TOLER e AMMI de maneira a compará-los e a selecionar aqueles que apresentassem alta adaptabilidade produtiva nas regiões produtoras de café do estado de Minas Gerais. Foram instalados e conduzidos experimentos em Três Pontas, Campos Altos e Capelinha, em delineamento de blocos casualizados, com quatro repetições e seis plantas por parcela. Os tratamentos foram constituídos por 33 genótipos do grupo Mundo Novo obtidos no Programa de Melhoramento Genético do Cafeeiro conduzido pelo Instituto Agronômico de Campinas (IAC). As avaliações de produção foram efetuadas ao longo de seis colheitas, as quais foram agrupadas em biênios. Cada combinação biênio x local foi considerada um ambiente, totalizando nove ambientes de estudo. Uma vez detectada a presença de interação genótipo x ambiente pelo teste de $\mathrm{F}$ de Snedecor, procedeu-se à análise de estabilidade, sendo a adaptação representada pela produtividade. Os métodos AMMI e TOLER foram semelhantes ao classificar os genótipos e ambientes e devem ser usados em conjunto em programas de melhoramento do cafeeiro para maior confiabilidade das informações, uma vez que suas interpretações são complementares. A estabilidade foi associada, nesse estudo, com baixa adaptabilidade. Os genótipos IAC 379-19, IAC 388-6-16 e IAC 403-1 apresentaram-se instáveis com alta adaptabilidade. Os genótipos IAC 2931 e IAC 480 se enquadram como desejáveis, pois associam estabilidade média e produtividade considerável.
\end{abstract}

Palavras-chave: Coffea arabica L., melhoramento genético, adaptabilidade, estabilidade fenotípica.

\section{Genotype $x$ environment interaction in Mundo Novo coffee genotypes by non- linear and multiplicative models}

\begin{abstract}
The purpose of this study was to evaluate the phenotypic adaptability and stability for yield in coffee genotypes of the cultivar "Mundo Novo" by using the methods TOLER and AMMI, as well as to select genotypes with high productive adaptability in the coffee growing regions of Minas Gerais. The experiments were carried out in Três Pontas, Campos Altos and Capelinha, Minas Gerais, Brazil, in a randomized complete block design with four repetitions and six plants per plot. The treatments consisted of 33 genotypes of cultivar "Mundo Novo" provided by the coffee plant breeding program of the Instituto Agronômico (IAC). The yield analyses were performed during six harvests, which were grouped in bienniums. Each combination biennium $x$ site was considered an environment totalizing nine environments. Once the genotype $x$ environment interaction was detected by the $F$ test of Snedecor, the stability analysis was done with the adaptation being represented by yield. The methods AMMI and TOLER were similar when classifying the genotypes and environments, and should be used together in coffee breeding programs in order to obtain greater reliability of information, as they are complementary. In this study the stability was associated with low adaptability. The IAC 379-19, IAC 388-6-16 and IAC 403-1 genotypes were unstable with high adaptability. The IAC 2931 and IAC 480 genotypes were classified as desirable due to average stability associated with reasonable yield.
\end{abstract}

Key words: Coffea arabica L., genetic breeding, adaptability, phenotypic stability. 


\section{INTRODUÇÃO}

Devido à sua rusticidade, alto potencial produtivo e boa qualidade do fruto, o grupo da cultivar Mundo Novo é um dos preferidos para plantio pelos agricultores brasileiros. Esses cafeeiros têm apresentado boa produtividade em quase todas as regióes cafeeiras do Brasil com clima apropriado para Coffea arabica L., demostrando ampla capacidade produtiva, boa longevidade e excelente rusticidade (FAZUoli et al., 2005).

Essa grande adaptação das seleçôes de Mundo Novo às mais diversas condiçôes de ambiente e a sua boa capacidade de combinação nas hibridaçôes evidenciam o interesse da pesquisa para a obtençấo de novas seleções desse cultivar em Minas Gerais. Contudo, a recomendação de genótipos não deve ser feita apenas com base no comportamento médio observado nos diferentes ambientes, uma vez que alguns deles apresentam melhores padrôes em ambientes específicos (Cardoso et al., 2007; Silveira et al., 2012).

Embora melhoristas em geral tendam a interpretar essa interação como negativa, por representar uma barreira ao ganho de seleção, VASCONCElos et al. (2010) ressaltam que interaçôes significativas associadas com características ambientais previsíveis representam uma oportunidade de exploração. A adaptação de genótipos a ambientes específicos pode fazer a diferença entre uma cultivar boa e uma excelente (Cardoso et al., 2012; Dias et al., 2009).

A melhor forma de tratar essa interação é avaliar os genótipos no maior número possível de ambientes e aplicar métodos que os classifiquem conforme a sua estabilidade e adaptabilidade (Regitano Neto et al., 2013). Destacamse na literatura os métodos que estimam a contribuição de cada genótipo para a interação (ecovalência), métodos que empregam a regressão linear, bilinear, ou não linear para definir a estabilidade e adaptabilidade, havendo ainda métodos náo paramétricos e métodos multiplicativos baseados em componentes principais (RAmalho et al., 2012).

Toler e Burrows (1998) propuseram o método de regressão não linear bissegmentado em que o índice ambiental é um parâmetro a ser estimado interativamente. $\mathrm{O}$ chamado método de TOLER procura identificar genótipos que mantenham a produtividade em níveis aceitáveis apesar do estresse nos ambientes desfavoráveis e que sejam responsivos quando as condiçóes ambientais melhoram. Assim, o genótipo avaliado pode apresentar dois padrôes de resposta, os quais são chamados de convexo e côncavo, referindo-se ao comportamento do genótipo em ambientes favoráveis e desfavoráveis, respectivamente. $\mathrm{O}$ primeiro designa o genótipo duplamente favorável, ou seja, que apresenta desempenho consistente em condições desfavoráveis e consegue explorar a melhoria do ambiente. Já o genótipo caracterizado como duplamente desfavorável é sensível em ambientes desfavoráveis e não responde à melhoria desse ambiente (RAmalho et al., 2012).
Porém, quando se trata de interação $\mathrm{G} \times \mathrm{A}$, os efeitos principais de genótipos e de ambientes são estatisticamente não aditivos (HueHn, 1990) e isso favorece os métodos multiplicativos, dentre os quais o modelo AMMI (efeitos aditivos principais e interaçáo multiplicativa), que é uma boa opção no tratamento dos dados e interpretação dos resultados tanto nos aspectos estatísticos quanto nos agronômicos (GAUCH, 2006). Esse modelo utiliza conjuntamente a análise de variância para os efeitos principais de genótipos e ambientes e a Análise dos Componentes Principais (ACP) para a interação. Para genótipos, procura identificar aqueles mais estáveis e adaptáveis e, para ambientes, permite realizar o zoneamento agronômico. Uma das vantagens creditadas ao modelo é que ele não procura explicar toda variação devida à interação e sim o padrão, descartando ruídos adicionais, incrementando assim a acurácia preditiva (DuARTE e Vencovsky, 1999; Gauch, 2006).

Apesar da importância da cultura do cafeeiro, são poucos os relatos na literatura que avaliam a adaptabilidade e a estabilidade de genótipos de café arábica no Brasil (Botelho et al., 2010; Carvalho et al., 2012; Nascimento et al., 2010). Pelo exposto, o objetivo deste estudo é avaliar a estabilidade e a adaptabilidade de genótipos de cafeeiro do grupo Mundo Novo pelos métodos TOLER e AMMI, de maneira a compará-los e a selecionar genótipos estáveis que apresentem alta adaptabilidade produtiva nas regióes produtoras do estado de Minas Gerais.

\section{MATERIAL E MÉTODOS}

Foram avaliados 33 genótipos de cafeeiro (Coffea arabica L.) do grupo Mundo Novo obtidos no Programa de Melhoramento Genético do Cafeeiro conduzido pelo Instituto Agronômico de Campinas (IAC) (Tabela 1). Os experimentos foram instalados na Fazenda Experimental da Epamig, situada no município de Três Pontas, na Fazenda Ouro Verde, situada em Campos Altos, e na Fazenda Resplendor, em Capelinha. Esses locais representam algumas das principais regiôes cafeeiras de Minas Gerais: Sul de Minas, Alto Paranaíba e Vale do Jequitinhonha, respectivamente.

As regióes escolhidas têm características ambientais definidas e distintas que influenciam sobremaneira o comportamento do cafeeiro (Tabela 2), o que permite melhor discriminação dos genótipos quanto a sua estabilidade e a sua adaptabilidade de comportamento (CARVAlHo et al., 2012).

O delineamento adotado foi de blocos casualizados, com quatro repetiçóes e seis plantas por parcela, no espaçamento de $3,8 \mathrm{~m}$ (entre linhas) $\times 0,8 \mathrm{~m}$ (entre plantas). Os tratos culturais e a condução do experimento foram feitos de acordo com as recomendaçôes técnicas para a cultura do cafeeiro.

As avaliaçôes de produçáo foram efetuadas ao longo de seis colheitas entre os meses de maio a julho. Foi obtida a produção em litros de café da roça, que posteriormente 
Tabela 1. Relação dos genótipos de Mundo Novo avaliados em três locais de Minas Gerais

\begin{tabular}{|c|c|c|c|c|c|}
\hline No & Genótipo & No & Genótipo & No & Genótipo \\
\hline 1 & IAC 382-7 & 12 & IAC 379-19 & 23 & IAC 388-6 14 \\
\hline 2 & IAC 471-11 & 13 & IAC 376-14 & 24 & IAC 388-6-16 \\
\hline 3 & IAC 2897 & 14 & IAC 500-11 & 25 & IAC 379-19-2 \\
\hline 4 & IAC 447 & 15 & IAC 46415 & 26 & IAC 464-2 \\
\hline 5 & IAC 387 14-11 & 16 & IAC 379-19-1 & 27 & IAC 502-9 P 13 \\
\hline 6 & IAC 502-9 & 17 & IAC 480 & 28 & IAC 388-6-13 \\
\hline 7 & IAC 403-1 & 18 & IAC 376-4-26 C 807 & 29 & IAC 502-11 \\
\hline 8 & IAC 2931 & 19 & IAC 388-6-16-2 & 30 & IAC 501-5-801 \\
\hline 9 & IAC 515-8 & 20 & IAC 464-1 E12-59 & 31 & IAC 501 \\
\hline 10 & IAC 50112 & 21 & IAC 500-15 C 722 & 32 & IAC 376-4-36 \\
\hline 11 & IAC 475 & 22 & IAC 500-11 P 1 & 33 & IAC 376-4-22 \\
\hline
\end{tabular}

Tabela 2. Regiôes geográficas, variáveis climáticas e caracterização dos locais de instalação dos experimentos no estado de Minas Gerais

\begin{tabular}{|c|c|c|c|}
\hline Características & Três Pontas & Campos Altos & Capelinha \\
\hline Tipo de solo & $\begin{array}{c}\text { Latossolo Vermelho } \\
\text { Distrófico }\end{array}$ & $\begin{array}{l}\text { Latossolo Vermelho } \\
\text { Amarelo Distrófico }\end{array}$ & $\begin{array}{c}\text { Latossolo Vermelho } \\
\text { Amarelo Húmico }\end{array}$ \\
\hline Textura & Argilosa & Argilosa & Argilosa \\
\hline Relevo & Ondulado & Plano & Ondulado \\
\hline Altitude & $900 \mathrm{~m}$ & $1.230 \mathrm{~m}$ & $820 \mathrm{~m}$ \\
\hline Latitude & $21^{\circ} 22^{\prime} 01^{\prime \prime} \mathrm{S}$ & $19^{\circ} 41^{\prime} 47^{\prime \prime} \mathrm{S}$ & $21^{\circ} 40^{\prime} \mathrm{S}$ \\
\hline Precipitação anual & 1.670 mm & 1.830 mm & $1.450 \mathrm{~mm}$ \\
\hline Temperatura anual & $20,1^{\circ} \mathrm{C}$ & $17,6^{\circ} \mathrm{C}$ & $21,3^{\circ} \mathrm{C}$ \\
\hline
\end{tabular}

foi convertida de volume para sacas de $60 \mathrm{~kg}$ de café beneficiado ha ${ }^{-1}$. Considerou-se rendimento médio 480 litros de café da roça para cada saca de $60 \mathrm{~kg}$ de café beneficiado, que corresponde ao rendimento médio adotado em todas as regiôes (CARvalHo et al., 2009).

As colheitas foram agrupadas em biênios, sendo que cada combinação biênio $\times$ local foi considerada um ambiente, totalizando nove ambientes empregados na análise, sendo os ambientes 1 a 3 no município de Três Pontas (TP); 4 a 6 em Campos Altos (CA); e 7 a 9 em Capelinha (C). Esse agrupamento das colheitas em biênios tem por objetivo minimizar a variação devida à bienalidade do cafeeiro (Bonomo et al., 2004; Botelho et al., 2010).

As análises estatísticas foram realizadas após a constatação da homogeneidade das variâncias, por meio do teste de Harttley, utilizando-se o aplicativo computacional SAS (SAS, 2009). Diante da significância da fonte de variação genótipos aplicou-se o teste de agrupamento de médias de Scott e Клотт (1974) com 5\% de significância, objetivando-se demonstrar o comportamento dos genótipos com base na média fenotípica e o efeito da seleção baseada na estabilidade dos genótipos. Uma vez detectada a presença de interação G×A pelo teste de F de Snedecor, procedeu-se à análise de estabilidade, que permite mensurar a adaptação e a estabilidade de produção de cada progênie avaliada, sendo a adaptaçáo representada pela produtividade. $\mathrm{O}$ modelo estatístico utilizado foi:
$Y_{i j k}=\mu+g_{i}+a_{k}+b_{j(k)}+g a_{i k}+e_{i j(k)}$

em que: $Y_{\mathrm{ijk}}$ : observação da ijk-ésima parcela no bloco $\mathrm{j}$ no local k que recebeu o genótipo i; $\mu$ : constante fixa associada a todas as observações (média fenotípica); $\mathrm{g}_{\mathrm{i}}$ : efeito fixo do i-ésimo genótipo; $\mathrm{a}_{\mathrm{k}}$ : efeito aleatório do k-ésimo ambiente, considerando $a_{k} \sim \operatorname{NMV}\left(0, \sigma_{a}^{2}\right) ; b_{j(k)}$ : efeito aleatório do j-ésimo bloco dentro do ambiente $k$, considerando $b_{j(k)} \sim \operatorname{NMV}\left(0, \sigma_{b}^{2}\right)$; $\mathrm{ga}_{\mathrm{i} \mathrm{k}}$ : efeito aleatório da ik-ésima interação genótipo com local, considerando $\mathrm{gl}_{\mathrm{ik}} \sim \operatorname{NMV}\left(0, \sigma_{\mathrm{gl}}^{2}\right) ; \mathrm{e}_{\mathrm{ij}(\mathrm{k})}$ : efeito aleatório do erro experimental associado à ij-ésima parcela dentro do ambiente $\mathrm{k}$, sendo $e_{\mathrm{ij}(\mathrm{k})}-\mathrm{NMV}\left(0, \sigma_{\mathrm{e}}^{2}\right)$.

Para análise de estabilidade e adaptabilidade utilizaram-se as metodologias de TOLER e AMMI, por meio do programa Estabilidade (Ferreira e Zambalde, 1997).

O método proposto por Toler e Burrows (1998) utiliza a análise de regressão bissegmentada não linear e adota o seguinte modelo:

$Y_{i j}=\alpha_{i}\left[Z_{j} \beta_{1 i}+\left(1-Z_{j}\right) \beta_{2 i}\right] \mu_{j}+\delta_{i j}+\bar{\varepsilon}_{i j}$

em que: $Y_{i j}$ : resposta média do i-ésimo genótipo no j-ésimo ambiente $j(i=1,2, \ldots, p$ genótipos; e $j=1,2, \ldots, q$ ambientes); $\alpha_{i}$ : parâmetro que reflete o valor da resposta do i-ésimo genótipo no ambiente de produtividade média $\left(\mu_{\mathrm{i}}=0\right) ; \beta_{1 \mathrm{i}}$ e $\beta_{21}$ : parâmetros que refletem a sensibilidade de resposta do i-ésimo genótipo nos ambientes de baixa $\left(\mu_{\mathrm{j}}<0\right)$ e de alta $\left(\mu_{i}>0\right)$ produtividade média, respectivamente; $\mu_{i}$ : parâmetro que reflete o efeito do j-ésimo ambiente; $\delta_{\mathrm{ij}}$ : desvio da regressão 
não linear (originalmente confundido no erro aleatório; $\bar{\varepsilon}_{\mathrm{ij}}$ : erro experimental médio; $Z$ : variável indicadora dummy, sendo $Z_{i}=1$ quando $\mu_{i} \leq 0$, e $Z_{j}=0$ quando $\mu_{i}>0$.

Com base nos teste de hipótese Ho: $\beta_{1 \mathrm{i}}=\beta_{21}$ e Ho: $\beta_{1 \mathrm{i}}=\beta_{21}=\beta_{\mathrm{i}}=1$, os genótipos foram enquadrados em cinco grupos, identificados pelas letras maiúsculas $\mathrm{A}, \mathrm{B}$, C, D, E, sendo: A: resposta convexa e duplo desejável; B: resposta linear simples e desejável somente em ambientes de alta qualidade (adaptabilidade específica a ambientes favoráveis); C: resposta linear não desviando da resposta média (adaptabilidade geral); D: resposta linear simples e desejável somente em ambientes de baixa qualidade (adaptabilidade específica a ambientes desfavoráveis); e E: resposta côncava e duplo indesejável.

O ajuste do modelo AMMI foi realizado em duas etapas distintas. A primeira consistiu em aplicar análise de variância para os efeitos aditivos, resultando em um resíduo de náo aditividade, o qual consiste da variação devida à interação G×A. Essa interação, representante da parte multiplicativa do modelo, foi tratada pela técnica algébrica da decomposição por valores singulares (DVS) (PEARson, 1901) aplicada na matriz de interação, permitindo a decomposiçáo de uma matriz por outra de posto menor (ECKART e Young, 1936). Essa decomposição visa captar em poucos componentes, ou eixos, a maior parte do padrão da interação, facilitando assim a interpretação dos resultados (RAMALHo et al., 2012).

$\mathrm{O}$ modelo AMMI encontra-se demonstrado abaixo:

$\mathrm{Y}_{\mathrm{ij}}=\mu+\mathrm{g}_{\mathrm{i}}+\mathrm{a}_{\mathrm{j}}+\sum_{\mathrm{k}=1}^{\mathrm{n}} \lambda_{\mathrm{ik}} \gamma_{\mathrm{ik}} \alpha_{\mathrm{jk}}+\rho_{\mathrm{ij}}+\varepsilon_{\mathrm{ij}}$

em que: $Y_{i j}$ : média do genótipo i no ambiente j; $\mu$ : média geral; $\mathrm{g}_{\mathrm{i}}$ e $\mathrm{a}_{\mathrm{j}}$ efeitos do i-ésimo genótipo e j-ésimo ambiente, respectivamente; $\lambda_{\mathrm{i}}: \mathrm{k}$-ésimo valor singular da matriz $\mathrm{G} \times \mathrm{A}$ (escalar); $\gamma_{i \mathrm{k}} \alpha_{\mathrm{i} k}$ : elementos correspondentes ao i-ésimo genótipo e j-ésimo ambiente, nos vetores $\gamma_{i \mathrm{k}}$ (vetor singular coluna) e $\alpha_{\mathrm{jk}}$ (vetor singular linha), respectivamente; n: número de componentes principais da interação $\mathrm{G} \times \mathrm{A}$ retidos no modelo; $\rho_{\mathrm{ij}}$ : resíduo da interação $\mathrm{G} \times \mathrm{A}$; e $\varepsilon_{\mathrm{ij}}$ : erro experimental médio. Para facilitar a visualização dos resultados, o método utiliza o gráfico chamado biplot, onde são plotados os escores da DVS referentes a genótipos e ambientes (GABRIEL, 1971).

\section{RESULTADOS E DISCUSSÃO}

Houve efeito significativo $(\mathrm{p}<0,05)$ pelo teste $\mathrm{F}$ para as fontes de variação genótipos, ambiente e interação genótipos $x$ ambiente. A existência da interação evidencia diferença no desempenho dos genótipos em relaçáo à produtividade nos diferentes locais estudados e justifica a avaliação de estabilidade e adaptabilidade desses genótipos.

Os genótipos se enquadraram nos cinco grupos estabelecidos pela metodologia de Toler (1998), a qual estabelece três requisitos necessários para que essa classificação ocorra: alta diversidade ambiental, precisão experimental e a real diversidade quanto aos padróes de resposta definidos pelo método. Dos nove ambientes avaliados (Tabela 3), cinco foram considerados desfavoráveis: Três Pontas no biênio 1 e no biênio 3, Campos Altos no biênio 1 e no biênio 3 e Capelinha no biênio 3. Com relação aos ambientes favoráveis, Capelinha no biênio 2 foi considerado o melhor pelo índice ambiental $(18,76 \mu . j)$.

Dentre os 33 genótipos avaliados, $90 \%$ se enquadram no padrão de resposta unissegmentado $(\mathrm{B}, \mathrm{C}, \mathrm{D})$, sendo $5 \%$ desses com resposta desejável em ambientes favoráveis (B), $76 \%$ com resposta não desviando da média (C) e $9 \%$ com resposta favorável em ambientes de qualidade pobre (D) (Tabela 4). Dentre esses 30 genótipos que se enquadram em B, C, D, 14 apresentaram produtividade acima da média geral, sendo classificados pelo teste de média nos quatro primeiros grupos. Nesse agrupamento destacam-se: quanto à adaptabilidade geral, o genótipo G24 e para adaptabilidade específica em ambientes desfavoráveis, o genótipo G7, os quais situaram-se no Grupo B pelo teste de média realizado. Esses dois genótipos são de interesse, em especial o G24, em função da heterogeneidade de ambientes em que o café é cultivado.

Apenas $10 \%$ dos genótipos apresentaram padrão de resposta bissegmentado (Grupo A e Grupo E). O destaque é para o genótipo G12, o único classificado como duplamente favorável (A) e que ainda apresentou a maior produtividade na média dos ambientes. Devido a essas características, esse genótipo ocupa o primeiro lugar no ordenamento, dentre os avaliados, de acordo com o conceito de genótipo ideal pelo método utilizado. Resultados divergentes foram encontrados por Rosse e Vencovsky (2000), que analisaram dados produtivos de feijão e constataram que os genótipos classificados com padrão $\mathrm{A}$ não estavam associados com médias elevadas. E apontaram a dificuldade de encontrar indivíduos duplamente desejáveis com alta produtividade e previsibilidade de comportamento.

No Grupo E destaca-se o comportamento do genótipo G8, cuja produtividade foi inferior apenas ao genótipo G12. Vale ressaltar que nem sempre os genótipos do Grupo A

Tabela 3. Resultados médios de produtividade de grãos de café por ambiente e índice de qualidade ambiental (IQA) estimados pelo método de Toler e Burrows (1998), avaliados nos municípios de Três Pontas (TP), Campos Altos (CA) e Capelinha (C)

\begin{tabular}{|cccr|}
\hline Identificação & Ambiente & Média (sacas ha-1) & IQA $\left(\mu_{\mathrm{j}}\right)$ \\
\hline TP 1 & TP (biênio 1) & 22,66 & $-7,59$ \\
\hline TP 2 & TP (biênio 2) & 32,27 & 2,12 \\
\hline TP 3 & TP (biênio 3) & 14,60 & $-15,64$ \\
\hline CA 1 & CA (biênio 1) & 27,48 & $-2,76$ \\
\hline CA 2 & CA (biênio 2) & 39,46 & 9,21 \\
\hline CA 3 & CA (biênio 3) & 28,34 & $-1,90$ \\
\hline C 1 & C (biênio 1) & 38,80 & 8,55 \\
C 2 & C (biênio 2) & 49,00 & 18,76 \\
C 3 & C (biênio 3) & 19,60 & $-10,65$ \\
\hline
\end{tabular}


Tabela 4. Classificação dos genótipos em função do teste de agrupamento de médias ScotT e KnotT (1974) e padrão de resposta definidos pelo método de Toler e Burrows (1998)

\begin{tabular}{|c|c|c|c|c|c|c|}
\hline \multirow[t]{2}{*}{ Classificação SK } & \multicolumn{6}{|c|}{ Padrão de classificação genotípica de resposta } \\
\hline & A & B & $\mathrm{C}$ & D & E & Porcentagem ${ }^{2}$ \\
\hline a & 12 & & & & & $3 \%$ \\
\hline$b$ & & & 24 & 7 & 8 & $10 \%$ \\
\hline c & & & $9 ; 17 ; 25 ; 33$ & 18 & 3 & $18 \%$ \\
\hline$d$ & & & $21 ; 22 ; 29 ; 30$ & 26 & & $16 \%$ \\
\hline e & & 13 & $1 ; 6 ; 14 ; 15 ; 16 ; 27$ & & & $22 \%$ \\
\hline$f$ & & & $4 ; 20 ; 28 ; 31$ & & & $9 \%$ \\
\hline g & & & $2 ; 10 ; 11 ; 19 ; 23$ & & & $15 \%$ \\
\hline $\mathrm{h}$ & & & $5 ; 32$ & & & $6 \%$ \\
\hline Porcentagem ${ }^{1}$ & $3 \%$ & $5 \%$ & $76 \%$ & $9 \%$ & $7 \%$ & \\
\hline
\end{tabular}

'Proporçăo de genótipos classificados em cada categoria do método de Toler e Burrows (1998); ${ }^{2}$ proporçáo de genótipos classificados em cada agrupamento do teste de ScotT e Кнотт (1974)

são os ideais em quaisquer condições. Para agricultores que empregam baixo nível tecnológico, um padrão $\mathrm{E}$ de resposta pode ser mais adequado quando associado a alta produtividade (Moraes et al., 2008). Dessa forma, o genótipo G8 pode ser indicado para essas condiçóes.

Esses resultados estão de acordo com os obtidos em outros trabalhos, nos quais a maioria dos genótipos são classificados nos grupos unissegmentados e apenas alguns nos grupos A e E (Moraes et al., 2008, Rosse e Vencovsky, 2000; Toler e Burrows, 1998). De acordo com Toler e Burrows (1998), essa característica pode estar relacionada com o nível de melhoramento de uma espécie. Assim, quanto maior o grau de melhoramento, menos divergente será o comportamento de cada indivíduo dentro da população. Vale ressaltar que os genótipos avaliados no presente trabalho foram obtidos de geraçóes avançadas de um programa de melhoramento (Pereira et al., 2010).

$\mathrm{Na}$ análise AMMI foram necessários três eixos para captar-se o padrão da interação, resultando em desvios náo significativos. Entretanto, a interpretação dos resultados em três dimensões foi dificultada pelo fato de os marcadores de genótipos e de ambientes terem ficado muito próximos entre si, o que confunde sua discriminação. Dessa forma, foram utilizados dois componentes principais, resultando no modelo AMMI-II. Nesse modelo, o terceiro eixo não é mais necessário em um nível de significância de 2\%, além de apresentar porcentagem da variação acumulada, devido à interação explicada, em 67\% (Tabela 5). Esse valor corrobora percentuais apresentados por outros autores para produtividade de grãos (ANNICCHIARICO et al., 2011; Ramburan et al., 2012; Sanchez-Garcia et al., 2012; WAMATU et al., 2003) e é considerado adequado por explicar a maior parte da variação padrão presente na interação. Utilizando-se a técnica de componentes principais, a variação total, devido à interação $\mathrm{G} \times \mathrm{A}$, pode ser explicada pelo menor número de linhas ou colunas da matriz de interação menos uma unidade. Como no presente estudo utilizaram-se nove ambientes, o número de eixos que podem ser utilizados para
Tabela 5. Quantidade de soma de quadrados captada, percentual de explicação e percentual de explicação acumulada para cada componente principal (CP)

\begin{tabular}{cccc|}
\hline CP & Autovalores & \% Explicação & \% Expl. acumulada \\
\hline 1 & $3.437,5537$ & 50,11 & 50,11 \\
\hline 2 & $1.158,2786$ & 16,89 & 67,00 \\
\hline 3 & 698,6477 & 10,18 & 77,18 \\
\hline 4 & 535,4225 & 7,80 & 84,98 \\
\hline 5 & 404,9546 & 5,90 & 90,88 \\
\hline 6 & 383,1869 & 5,58 & 96,46 \\
\hline 7 & 132,7463 & 1,93 & 98,39 \\
\hline 8 & 108,3323 & 1,61 & 100,00 \\
\hline
\end{tabular}

explicar a variação total devido à interação é oito. Entretanto, os primeiros eixos do espaço amostral captam a maior parte da variação presente, chamada de padrão. Essa variação é útil ao melhoramento, pois as estimativas geradas por ela podem ser consideradas precisas. Por outro lado, quanto mais eixos principais forem adicionados, maior ruído se adiciona às estimativas, diminuindo sua precisão.

A interpretação do modelo AMMI-II é facilitada pelo gráfico de dispersão (Figura 1), cuja interpretação é feita observando-se a magnitude e o sinal dos escores dos CPs. Para o biplot AMMI-II, atenção é dada aos marcadores de genótipos ou ambientes que se encontram mais próximos da origem do plano cartesiano, ou seja, com valores mais próximos da coordenada $[0,0]$. Isso ocorre porque marcadores situados nessa região contribuíram em menor proporção para a interação. O uso do gráfico AMMI-II impossibilita a visualização direta da adaptabilidade produtiva dos genótipos e dos ambientes como feita no AMMI-I, onde a produtividade são as abscissas do gráfico. Para contornar essa situação, como indicado por DuARTE e Vencovsky (1999), juntamente com a identificação dos marcadores encontra-se o seu posicionamento em relação à média aritmética de produtividade para genótipos e ambientes.

Em função do elevado número de marcadores de genótipos e da proximidade entre eles, a visualização de alguns é difícil, 

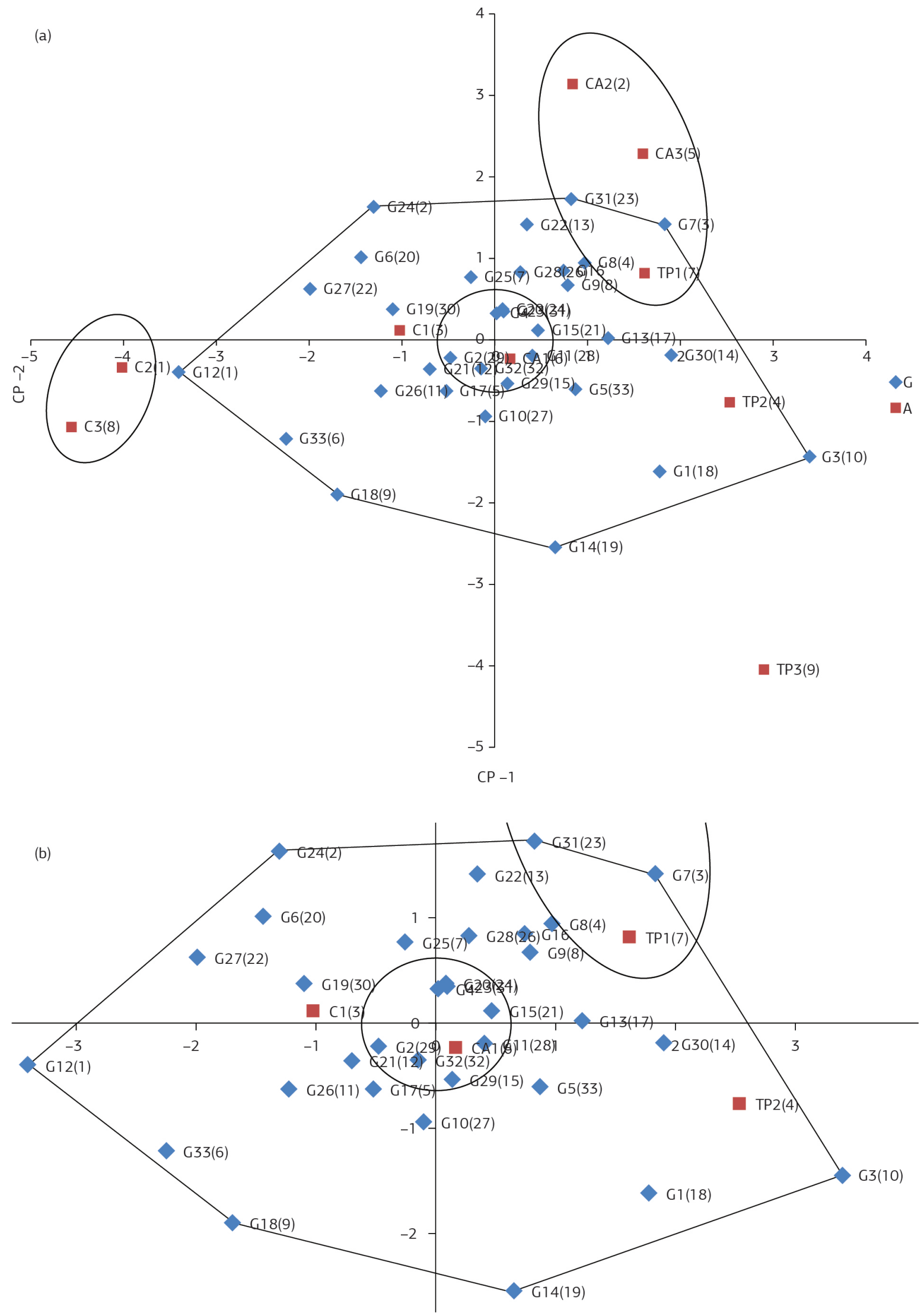

Figura 1. Biplot AMMI-II: (a) Marcadores em forma de losango referem-se a genótipos e os de forma quadrada, a ambientes; o número entre parênteses nos marcadores indica o ordenamento quanto à produtividade; CP-1: eixo do primeiro componente principal, que explicou $50,11 \%$ da variação existente na interação genótipo por ambiente; CP-2: eixo do segundo componente principal, com 16,89\% de explicação da variação devido à interação; (b) detalhe no ponto de maior concentraçáo de marcadores de genótipos em (a) 
dessa forma foi feita uma ampliação do ponto de maior concentraçáo de marcadores do genótipo. Visualizando-se o biplot AMMI-II constata-se que os genótipos mais estáveis são os de número G32(32), G4(25), G20(24), G2(29), G23(31) G29(15), G11(28) e G15(21), os quais estão contidos pelo círculo central. Quanto aos ambientes, o mais estável é o CA1, seguido pelo C1. Inversamente, os genótipos mais instáveis, definidos pela maior distância da origem $[0,0]$ e formadores do polígono que contém todos os outros genótipos foram os identificados como G12(1), G18(9), G14(19), G3(10), G7(3), G31(23) e G24(2). Os ambientes mais instáveis foram TP3, C3, C2, CA2 e CA3.

De acordo com Duarte e Vencovsky (1999), a estabilidade genotípica refere-se à previsibilidade de comportamento, a qual indica a amplitude adaptativa dos genótipos. Porém a estabilidade é de pouca importância para o melhoramento quando não está associada a alta produtividade (RAMALHo et al., 2012). Baseando-se nessa premissa, a previsibilidade dos genótipos classificados como mais estáveis neste trabalho não é desejável, uma vez que a estabilidade foi inversamente proporcional à adaptabilidade.

Procurando-se uma estabilidade intermediária, mas associada à produtividade considerável, destacam-se os genótipos G8(4), G17(5), G25(7) e G9(8). Os resultados indicam que na instabilidade encontram-se ótimas oportunidades para o melhoramento do cafeeiro, uma vez que os genótipos mais instáveis foram os mais produtivos. A constatação desse fato, quando se busca adaptabilidade restrita, reforça ainda mais a positividade da interação no melhoramento. Os genótipos menos desejáveis, que além de serem instáveis foram pouco produtivos, são: G31(23), G6(20), G27(22), G19(30), G10(27), G5(33), G31(23) e G23(31).

A estabilidade associada a ambientes indica confiança no ordenamento dos genótipos avaliados, uma vez que a sua classificação deve-se, principalmente, aos efeitos genotípicos (Duarte e Vencovsky, 1999). Enquadram-se nessa categoria os ambientes CA1 e C1. Uma vez que nesses ambientes a interação é praticamente nula, a seleção é facilitada, pois a alteração no ordenamento dos genótipos quanto à produtividade ocorre em magnitude reduzida. Pode-se dizer que a repetibilidade no ordenamento ao longo das colheitas é elevada, portanto os genótipos podem ser selecionados precocemente em ambientes semelhantes.

Ambientes podem também ser agrupados de acordo com a semelhança do padrão de interação apresentado por eles, formando assim o zoneamento agronômico. Procedendo-se dessa maneira, pode-se perceber que existem três agrupamentos. No primeiro grupo encontram-se os ambientes $\mathrm{C} 3$ e $\mathrm{C} 2$, no segundo, os ambientes $\mathrm{CA} 1$ e $\mathrm{C} 1$ e, no terceiro grupo, os ambientes CA2, CA3 e TP1. Os ambientes TP2 e TP3 são dissimilares em relação aos outros, não se agrupando com nenhum deles.
De acordo com as propriedades do modelo AMMI, informaçóes importantes podem ser obtidas das combinaçóes genótipos-ambientes, cujos efeitos podem ser positivos ou negativos. Para isso, basta observar-se o produto dos escores entre marcadores de ambos os fatores. Efeitos favoráveis, nos quais a interação é capitalizada em favor do genótipo, são obtidos quando o produto entre eles é positivo. Como exemplo, cita-se as interaçóes positivas entre o genótipo G12 e os ambientes $\mathrm{C} 2$ e C3. O contrário também se observa entre o genótipo G24 e o ambiente TP2, onde o efeito da interação prejudicou o desempenho do genótipo.

\section{CONCLUSÃO}

Os métodos AMMI e TOLER foram semelhantes na classificaçáo dos genótipos e ambientes, devendo ser usados em conjunto em programas de melhoramento do cafeeiro para maior confiabilidade das informaçôes, uma vez que suas interpretaçóes são complementares. A estabilidade foi associada, neste estudo, com baixa adaptabilidade. Os genótipos IAC 379-19, IAC 388-6-16 e IAC 403-1 apresentaram-se instáveis, com alta adaptabilidade. Os genótipos IAC 2931 e IAC 480 se enquadram como desejáveis, pois apresentaram estabilidade média e produtividade aceitável.

\section{AGRADECIMENTOS}

Ao Instituto Nacional de Ciência e Tecnologia (INCT-Café), ao Conselho Nacional de Desenvolvimento Científico e Tecnológico (CNPq) e ao Consórcio de Pesquisa Café pelo suporte financeiro ao projeto, ao $\mathrm{CNPq}$ pela concessão da bolsa PNPD (JCR) e aos proprietários da Fazenda Ouro Verde e da Fazenda Resplendor pela disponibilização das áreas experimentais.

\section{REFERÊNCIAS}

ANNICCHIARICO, P.P.; PECETTI, L.; ABDELGUERFI, A.; BOUIZGAREN, A.; CARRONI, A.M.; HAYEK, T.; BOUZINA, M.M.; MEZNI, M. Adaptation of landrace and variety germplasm and selection strategies for lucerne in the Mediterranean basin. Field Crops Research, v.120, p.283-291, 2011. http://dx.doi.org/10.1016/j. fcr.2010.11.003

BONOMO, P.; CRUZ, C.D.; VIANA, J.M.S.; PEREIRA, A.A.; OLIVEIRA, V.R.; CARNEIRO, P.C.S. Avaliaçáo de Progênies obtidas de cruzamenos de descendentes do Híbrido de Timor com as cultivares Catuaí Vermelho e Catuaí Amarelo. Bragantia, v.63, p.207-219, 2004. http://dx.doi.org/10.1590/S0006-87052004000200006

BOTELHO, C.E.; REZENDE, J.C.; CARVALHO, G.R.; CARVALHO, A.M; ANDRADE, V.T.; BARBOSA, C.R. Adaptabilidade e estabilidade 
fenotípica de cultivares de café arábica em Minas Gerais. Pesquisa Agropecuária Brasileira, v.45, p.1404-1411, 2010. http://dx.doi. org/10.1590/S0100-204X2010001200010

CARDOSO, M.J.; CARVALHO, H.W.L.; GAMA, E.E.G.; SOUZA, E.M. Estabilidade do rendimento de grãos de variedades de Zea mays L. no Meio-Norte brasileiro. Revista Ciência Agronômica, v.38, p.78-83, 2007.

CARDOSO, M.J.; CARVALHO, H.W.L.; ROCHA, L.M.P.; PACHECO, C.A.P.; GUIMARÃES, L.J.M.; GUIMARÁES, P.E.O.; PARENTONY, S.N.; OLIVEIRA, I.R. Identificaçáo de cultivares de milho com base na análise de estabilidade fenotípica no Meio-Norte brasileiro. Revista Ciência Agronômica, v.43, p.346-353, 2012. http:// dx.doi.org/10.1590/S1806-66902012000200018

CARVALHO, G.R.; BOTELHO, C.E.; BARTHOLO, G.F.; PEREIRA, A.A.; NOGUEIRA, A.M.; CARVALHO; A.M. Comportamento de progênies $\mathrm{F}_{4}$ obtidas por cruzamento de Icatu com Catimor. Ciência e Agrotecnologia, v.33, p.47-52, 2009. http://dx.doi.org/10.1590/ S1413-70542009000100006

CARVALHO, A.M.; MENDES, A.N.G.; BOTELHO, C.E.; OLIVEIRA, A.C.B.; REZENDE, J.C.; REZENDE, R.M. Desempenho agronômico de cultivares comerciais de café resistentes à ferrugem no Estado de Minas Gerais, Bragantia, v.71, p.481-487, 2012. http:// dx.doi.org/10.1590/S0006-87052013005000007

DIAS, F.T.C.; DIAS, F.T.C.; PITOMBEIRA, J.B.; TEOFILO, E.M.; BARBOSA, F.S. Adaptabilidade e estabilidade fenotípica para o caráter rendimento de grãos em cultivares de soja para o Estado do Ceará. Revista Ciência Agronômica, v.40, p.129-134, 2009.

DUARTE, J.B.; VENCOVSKY, R. Interaçáo genótipos x ambientes: uma introdução à análise AMMI. Ribeirão Preto: Sociedade Brasileira de Genética, 1999. 60p. (Série Monográfica, 9).

ECKART, C.; YOUNG, G. The approximation of one matrix by another of lower rank. Psychometrika, v.1, p.211-218, 1936. http:// dx.doi.org/10.1007/BF02288367

FAZUOLI, L.C.; GUERREIRO FILHO, O.; SILVAROLLA, M.B.; MEDINA FILHO, H.P., CARVALHO, A. Avaliação das cultivares Mundo Novo, Bourbon Amarelo e Bourbon Vermelho de Coffea arabica L. em Campinas, SP. Bragantia, v.64, p.533-546, 2005. http:// dx.doi.org/10.1590/S0006-87052005000400003

FERREIRA, D.F.; ZAMBALDE, A.L. Simplificação de algumas técnicas especiais da experimentação agropecuária no MAPGEN e softwares correlatos. In: CONGRESSO DA SOCIEDADE BRASILEIRA DE INFORMÁTICA, 1., 1997, Belo Horizonte. Anais... Belo Horizonte: Sociedade Brasileira de Informática, 1997. p.285-291.

GABRIEL, K.R. The biplot graphic of matices with application to principal component analysis. Biometrika, v.58, p.453-467, 1971. http://dx.doi.org/10.1093/biomet/58.3.453

GAUCH, H.G. Statistical analysis of yield trials by AMMI and GGE. Crop Science, v.46, p.1488-1500, 2006. http://dx.doi.org/10.2135/ cropsci2005.07-0193

HUEHN, M. Nonparametric measures of phenotypic stability. Part I: theory. Euphytica, v.47, p.195-201, 1990.

MORAES, L.K.; MOURA, M.F; VENCOVSKY, R.; PINHEIRO, J.B. Adaptabilidade e Estabilidade Fenotípica em Soja Avaliada pelo método de Toler. Bragantia, v.67, p.275-284, 2008. http://dx.doi. org/10.1590/S0006-87052008000200003
NASCIMENTO, M.; FERREIRA, A.; FERRÃO, R.G.; CAMPANA, A.C.M.; BHERING, L.L.; CRUZ, C.D.; FERRÃO, M.A.G.; FONSECA, A.F.A. Adaptabilidade e estabilidade via regressão não paramétrica em genótipos de café. Pesquisa Agropecuária Brasileira, v.45, p.41-48, 2010. http://dx.doi.org/10.1590/S0100-204X2010000100006

PEARSON, K. On lines and planes of closet fit systems of points in space. Philosophical Magazine, v.2, p.559-572, 1901.

PEREIRA, A.A.; CARVALHO, G.R.; MOURA, W.M.; BOTELHO, C.E.; REZENDE, J.C.; OLIVEIRA, A.C.B.; SILVA, F.L. Cultivares, origem e suas características. In: REIS, P.R.; CUNHA, R.L. (Org.). Café arabica: do plantio a colheita. 2010. v.1, p.163-221.

RAMALHO, M.A.P.; SANTOS, J.B.; ABREU, A.F.B.; NUNES, J.A.R. Aplicaçôes da Genética Quantitativa no Melhoramento de Plantas Autógamas. Lavras: Editora UFLA, 2012. 522p.

RAMBURAN, S.; ZHOU, M.; LABUSCHAGNE, M. T. Investigating test site similarity, trait relations and causes of genotype $\times$ environment interactions of sugarcane in the Midlands region of South Africa. Field Crops Research, v.129, p.71-80, 2012. http://dx.doi.org/10.1016/j. fcr.2012.01.017

REGITANO NETO, A.; RAMOS JUNIOR, E.U.; GALLO, P.B., FREITAS, J.G.; AZZINI, L.E. Comportamento de genótipos de arroz de terras altas no estado de São Paulo. Revista Ciência Agronômica, v.44, p.512-519, 2013. http://dx.doi.org/10.1590/ S1806-66902013000300013

ROSSE, L.N.; VENCOVSKY, R. Modelos de regressão não linear aplicados ao estudo da estabilidade fenotípica de genótipos de feijão no estado do Paraná. Bragantia, v.59, p.99-107, 2000. http://dx.doi. org/10.1590/S0006-87052000000100016

SANCHEZ-GARCIA, M.; ALVARO, F.; MARTIN-SANCHEZ, J.A.; SILLERO, J.C.; ESCRIBANO, J.; ROYO, C. Breeding effects on the genotype $\times$ environment interaction for yield of bread wheat grown in Spain during the 20th century. Field Crops Research, v.126, p.79-86, 2012. http://dx.doi.org/10.1016/j.fcr.2011.10.001

SCOTT, A.J.; KNOTT, M.A. Cluster analysis method for grouping means in the analysis of variance. Biometrics, v.30, p.507-512, 1974. http://dx.doi.org/10.2307/2529204

SILVEIRA, L.C.I.; KIST, V.; PAULA, T.O.M.; BARBOSA, M.H.P.; OLIVEIRA, R.A.; DAROS, E. Adaptabilidade e estabilidade fenotípica de genótipos de cana-de-açúcar no estado de Minas Gerais. Ciência Rural, v.42, p.587-593, 2012.

STATISTICAL ANALISYS SYSTEM INSTITUTE - SAS. SAS/ STAT: user's Guide. Version 9.2. Cary: SAS Institute, 2009. 7869p.

TOLER, J. E.; BURROWS, P. M. Genotypic performance over environmental arrays: A non-linear grouping protocol. Journal of Applied Statistics, v.25, p.131-143, 1998. http://dx.doi. org/10.1080/02664769823368

VASCONCELOS, E.S.; REIS, M.S.; CRUZ, C.D.; SEDIYAMA, T.; SCAPIM, C.A. Adaptability and stability of semilate and late maturing soybean genotypes in Minas Gerais state. Acta Scientiarum Agronomy, v.32, p.411-415, 2010. http://dx.doi.org/10.4025/ actasciagron.v32i3.8249

WAMATU, J.N.; THOMAS, E.; PIEPHO, H.P. Responses of different arabica coffee (Coffea arabica L.) clones to varied environmental conditions. Euphytica, v.129, p.175-182, 2003. http://dx.doi. org/10.1023/A:1021927302410 